Pak. J. Agri., Agril. Engg., Vet. Sci., 2020, 36 (1): 61-67

ISSN: 1023-1072 (Print), ISSN: 2663-7863 (Online)

https://doi.org/10.47432/pjaaevs.2020.36.1.9

\title{
PREVALENCE OF HAEMOPROTOZOAN DISEASES IN EQUINES OF NORTHERN REGION OF SINDH, PAKISTAN
}

\author{
M. A. Kumbhar ${ }^{1}$, M. G. Shah ${ }^{2}$, J. A. Gadahi ${ }^{1}$, Z. A. Laghari ${ }^{1 *}$ and M. Kumbhar ${ }^{3}$ \\ ${ }^{1}$ Department of Veterinary Parasitology, ${ }^{2}$ Department of Anatomy and Histology, \\ ${ }^{3}$ Department of Livestock and Management, Sindh Agriculture University Tandojam, Pakistan
}

\begin{abstract}
Haemoprotozoan infections causes devasting loss to the livestock population through mortality and morbidity thereby reducing their production and lowered working efficiency. The present study was conducted to investigate the haemoprotozoan infection in equines in the district Larkana in northern Sindh, Pakistan. A total of 300 blood samples were collected from different species of equines in various localities of Larkana. The study was carried on stray and reared equines, including horses, donkeys and mules. The overall prevalence rate of protozoan infection in equines was found as $23.33 \%$ (70 animals) at different talukas/tehsils of district Larkana. Equine species wise haemoprotozoan infection was recorded as $7.69 \%, 24.11 \%$ and $20 \%$ in horses, donkeys and mules, respectively. Overall age-wise protozoan prevalence was determined as $18.5 \%$ in below 2 year and $23.80 \%$ in above 2 years age group. Whereas, in horses the infection rate was noted as $7.69 \%$ in above 2 years age group. The donkeys, above 2 years age group were susceptible for haemoprotozoan infections, which was recorded as $24.70 \%$ as compared to below 2 years age group $(18.51 \%)$. In case of mules, the infection rate was recorded as $20 \%$ in above 2 years of age group. Overall gender-wise protozoan prevalence was found $43.46 \%$ in male equines, whereas in female, it was $21.73 \%$. Equine species wise infection was recorded high in male of horses (9.09\%), donkeys $(24.13 \%)$ and mule $(20 \%)$ as compared to female horses $(0 \%)$, donkeys $(23.80 \%)$ and mule $(0 \%)$. Housing wise prevalence was recorded as high $(51.51 \%)$ in chhapra than open $(15.97 \%)$ and paka $(24.39 \%)$. The management wise infection was recorded as $100 \%$ in stray equines as compared to reared ones (22.81\%). The current study provides a baseline data on the prevalence of haemoprotozoans in equines in northern Sindh which may be helpful in designing control strategies for infectious diseases in equines.
\end{abstract}

Keywords: diagnosis, equines, haemoprotozoa, prevalence, Sindh

\section{INTRODUCTION}

Parasitic infections are the major cause of the equine diseases with significant economic losses in tropical as well as subtropical regions (Velusamy et al., 2014). Equines are exposed to various parasitic diseases including haemoprotozoan infections that affect the health of the animal resulting in the severe morbidity and mortality which poses a serious economic loss (Ananda et al., 2009; Krishnamurthy et al., 2016). Haemoprotozoan infections cause devasting losses with the mortality in equines has been reported due to the diseases caused by several protozoal parasites including Trypanosma, Babesia, Theileria and Anaplasma (Mattiolo et al., 1994; Salih et al., 2015). These parasites can cause chronic infection with their presence in blood (Mattiolo et al., 1994).

Corresponding author: laghari_sau@yahoo.com
The haemoprotozoan parasites are mainly transmitted by arthropod vectors including Tsetse fly (Glossina spp.) and several tick species or occasionally through blood transfusion/ contamination (Salih et al., 2015). These haemtophagus insect species are not only responsible for disease transmission but also cause anemia, disturbances in mental health and other blood associated complications with emaciation, anorexia, fever and death in acute cases (Ananda et al., 2009; Maharana et al., 2016). The haemoprotozoan parasites are prevalent in tropics due to favorable environment for vector survival, their growth or reproduction (Krishnamurthy et al., 2016).

The diseases caused by Trypanosma, Babesia, Theileria and Anaplasma are among the major diseases of equines causing serious economic loss to the farmers. Trypanosomiasis, most widely distributed of the pathogenic animal protozoan infection, is caused by different 
species of trypanosomes that includes Trypanosoma evansi, Trypanosoma congolese, Trypanosoma brucei, Trypanosoma equiperdum etc. Death in equids has been reported due to the disease caused by these parasites due to their effect on central nervous system (Soulsby, 1982; Urquhart et al., 1996). In equine babesiosis caused by Babesia equi and Babesia caballi (Friedhoff et al., 1990; Mehlhorn and Schein, 1998). While Theileria is caused by Theileria annulata and Theileria parva. Both of these protozoans are transmitted by 14 species of the Ixodid tick belonging to 3 genera Hyalomma, Dermacentor and Rhiphicephalus, are endemic in tropic and sub-tropic area of the world (Ali et al., 1996; Joanne et al., 2003).

Equine including horse, donkey (asses) and mules are important but neglected livestock species which play a significant role in the economy of sub-tropical regions of Asia and Africa (Goraya et al., 2013; Fielding, 1991). In Asia, Pakistan is considered as one of the largest equine populated areas with $0.4,5.3$ and 0.2 million heads of horses, asses and mules, respectively, during the year 2017-2018 (GoP, 2018). In the areas like deserts or mountainous ranges which are not suitable for proper agriculture or livestock production, equinesare considered as a main source of transportation or agricultural purposes (Goraya et al., 2013; Fielding, 1991).

Data regarding the prevalence of ticks and their role as a vector for transmitting haemoprotozoan shows that different livestock species are frequently affected by different species of ticks in various geo-ecological zones of Pakistan (Jabbar et al., 2015). Several attempts have been made to collect data regarding haemoprotozoan species infecting livestock species but their prevalence in equines is still a mystery as no proper surveillance have been reported in Pakistan. Epidemiological surveillance is an important aspect in controlling haemoprotozoan infection.

The present study was conducted to identify and determine the prevalence of haemoprotozoan parasites of equines in northern parts of Sindh and to assess their relationship with ectoparasites, production system, breed and sex of the animals. Therefore, present data regarding the prevalence of blood parasites can be useful in policy making regarding the control/preventive strategies against these diseases.

\section{MATERIALS AND METHODS Collection of blood sample}

Stratified random sampling has been used to collect 300 blood samples of equine (Horses, donkey and Mules) from four different taluka/ tehsil (Ratodero, Larkana, Bakrani, and Dokri) of district Larkana, Sindh, Pakistan.

During the sampling, data regarding housing systems (open, paka and chhapra), age distribution (below 2 year and above 2 year), gender (male and female) and management systems (reared and stray) was collected in order to categorize the disease occurrence and effect of different environmental factors on disease prevalence.

Blood was collected from each animal with sterile needle and syringe $(3 \mathrm{ml})$ from jugular vein and transferred into vacutainer containing $5.4 \mathrm{mg}$ ethylene diamine triatic acid (EDTA), and was slowly and gently mixed to avoid Hemolysis. After blood collection, vacutainers were properly labeled with the name of owner, species, breed, patient, date and time. Samples were transferred to the Central Veterinary Diagnostic Laboratory (CVDL) sub-center Larkana for further process. The initial blood smear analysis was done at CVDL using thin blood smear and then were transported to the Department of Veterinary Parasitology, Faculty of Animal Husbandry and Veterinary Sciences, Sindh Agriculture University, Tandojam for further confirmation.

\section{Preparation of blood smear and examination} For microscopy, blood smears were made according to lqbal et al. (2006). The slides were hold by edge to avoid the contamination of slide area where blood smear was to be made. Pin drop of blood were placed on the one third side of glass slide and with the help of another slide spread the blood drop proper way, blood was spread across edge of the slide at $45^{\circ}$ angle, smear on the slide was dried by waving in air. Without any shrinkage or rupturing of the red blood cells, the slides were immediately fixed in absolute methyl alcohol (Merck, Germany) for the one minute. Staining of the slides was done in $10 \%$ solution of Giemsa stain (Giemsa solution Merck, Germany) for the five minute and the slides were rinsed with the distilled water. Prepared slides were examined including a drop of oil immersion on 40x then 100x objectives in a binocular microscope for the identification of blood protozoans with the keys developed by Adam et al. (1971). 


\section{Data management and analysis}

During the sampling, owner's name, animal ID, sex, age, and body condition score were recorded. Data of each animal's parasitological examination were inserted in to MS-excel sheets during the initial phase which then was transferred to the Statistical Package for the Social Sciences (SPSS) software Version 20.0 before analysis. T-test and One-Way ANOVA was used to express results and compare variables.

\section{RESULTS}

The present study was conducted to determine the prevalence of haemoprotozoa by using conventional (microscopy) method in in equines of district Larkana of northern Sindh. A total of 300 blood samples were collected from each taluka/ tehsil of district Larkano. Babesia and Theileria were detected inside the RBC with Babesia which was characterized by their typical pea-shape, round and oval commonly seen single or in pair, whereas, Theileriashow spherical, ovoid and maltes cross shape body (Figure 1 and 2).

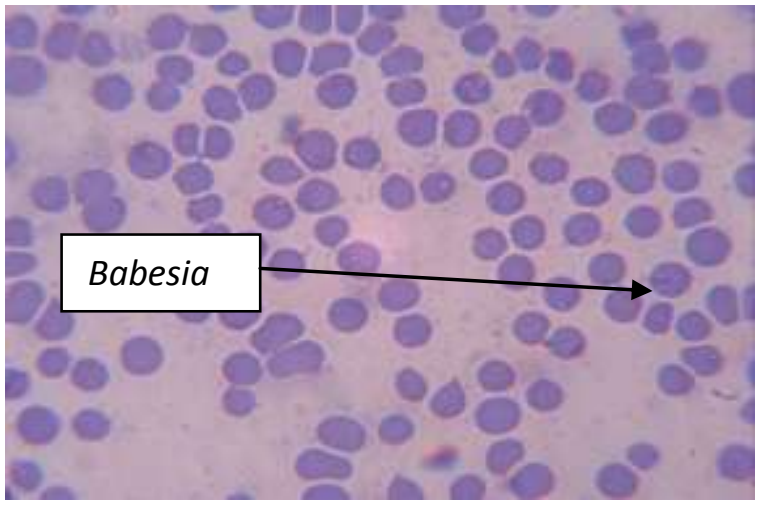

Figure 1. Giemsa Stained blood smear of equine showing Babesia in RBCs

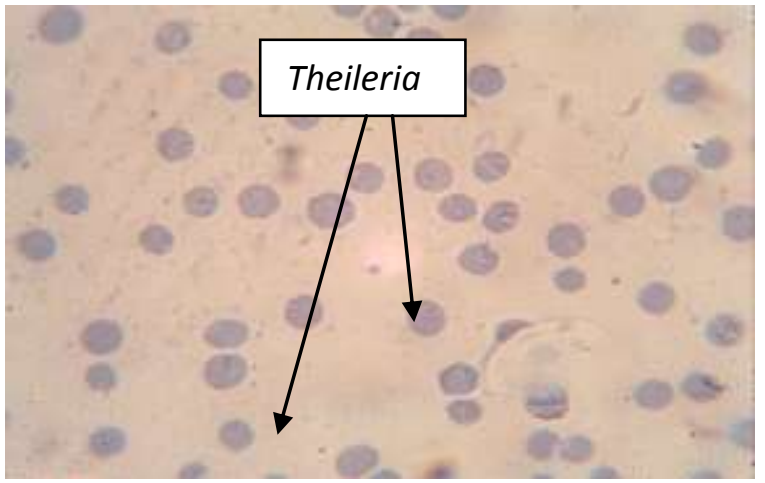

Figure 2. Giemsa Stained blood smear of equine showing Theileria in RBCs
Data revealed that overall prevalence of haemoprotozoa in equines were moderate at all sampling areas with highest in Bakrani, while lowest in Tehsil Dokri was recorded (Figure 3).

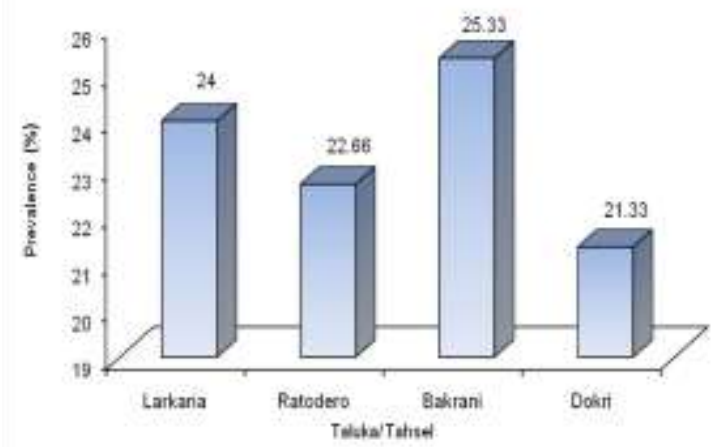

Figure 3. The prevalence of haemoprotozoan in equines in district Larkana

While at the same time analysis of prevalence of haemoprotozoa different species of equines show that infection rate was higher in Donkeys as compared to horses and mules (Figure 4).

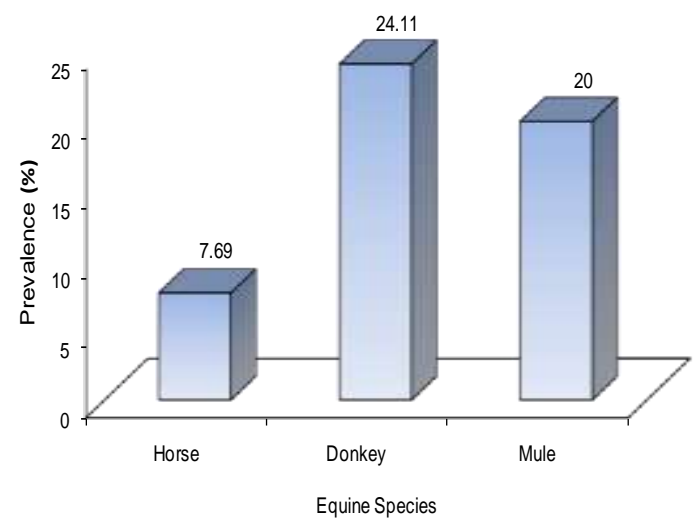

Figure 4. The prevalence of haemoprotozoan in different equine species in district Larkana

During the present study, prevalence based on the locality in different species of equine was also recorded. Data indicates that only a single horse was found infected with parasites in tehsil Dokri of the district Larkana. While, donkeys were found infected in all sampling areas with being highest infection rate in Larkana tehsil; followed by Ratodero, Bakrani and Dokri. Moreover, only one mule among the sampled animals was found positive for blood parasites at tehsil Larkana (Table 1). 
Table 1. The prevalence percentage of haemoprotozoans in different equine species at various localities of district Larkana

\begin{tabular}{|l|l|l|l|}
\hline Area & Horse & Donkey & Mule \\
\hline Larkana & $0 \%$ & $25 \%$ & $50 \%$ \\
\hline Ratodero & $0 \%$ & $24.63 \%$ & $0 \%$ \\
\hline Bakrani & $0 \%$ & $24.32 \%$ & $0 \%$ \\
\hline Dokri & $12.5 \%$ & $22.38 \%$ & $0 \%$ \\
\hline Total & $7.69 \%$ & $24.11 \%$ & $20 \%$ \\
\hline
\end{tabular}

Furthermore, the prevalence of protozoal species infecting equines at different localities of district Larkana was recorded. Data indicates that the prevalence of Theileria was highest as compared to Babesia with the prevalence of $70 \%$ and $30 \%$, respectively. While, no any animal was found infected with Trypanosoma. The area wise prevalence shows a highest prevalence of Theileria in Dokri, followed by Bakrani, Larkana and Ratodero. While, Bebesia infection was recorded highest in Ratodero and lowest in Dokri Larkana (Table 2).

Table 2. The prevalence percentage of haemoprotozoans at various localities of district Larkana

\begin{tabular}{|l|l|l|l|}
\hline Area & Babesia & Theileria & Trypanosoma \\
\hline Larkana & $33.33 \%$ & $66.67 \%$ & $0 \%$ \\
\hline Ratodero & $41.18 \%$ & $58.82 \%$ & $0 \%$ \\
\hline Bakrani & $26.32 \%$ & $73.68 \%$ & $0 \%$ \\
\hline Dokri & $18.75 \%$ & $81.52 \%$ & $0 \%$ \\
\hline
\end{tabular}

Moreover, animal specie wise prevalence indicates that Theileria infection was highest $(100 \%)$ in horses where no any case of Babesia or Trypanosoma was recorded. While, donkey was found infective predominantly with Theileria (69.12\%), followed by Babesia (30.88\%), with no any single case of Trypanosoma was recorded.

During the present study, only one mule was found infected with Theileria, while no any other protozoal infection was recorded in the study area. Moreover, age-wise prevalence in different equine species was recorded. These data indicate that due to lower sample size, the samples collected from horses and mules comprised of age of above 2 years of age, while, samples collected from donkeys were from both young (below 2 years) and aged (above 2 years) (Table 3).

Table 3. Age-wise prevalence percentage of different haemoprotozoan in equines at district Larkana

\begin{tabular}{|l|l|l|l|}
\hline $\begin{array}{l}\text { S. } \\
\text { No. }\end{array}$ & Animals & Below 2 years & Above 2 years \\
\hline 1 & Horse & $0 \%$ & $7.69 \%$ \\
\hline 2 & Donkey & $18.51 \%$ & $24.7 \%$ \\
\hline 3 & Mule & $0 \%$ & $20 \%$ \\
\hline Total & $18.51 \%$ & $23.8 \%$ \\
\hline
\end{tabular}

Gender-wise prevalence of haemoprotozoan in horses at district Larkana was observed as 9.09 prevalence in male, while no any female was found infected. In case of donkeys, the infection rate was $24.13 \%$ in males and $23.80 \%$ in females. Whereas, in case of mules, only one was found infected which accounts for $20 \%$ of the samples animals which was male (Table 4).

Table 4. Gender-wise prevalence percentage of haemoprotozoan in equines at district Larkana

\begin{tabular}{|l|l|l|l|}
\hline S. No. & Animals & Male & Female \\
\hline 1 & Horse & $9.09 \%$ & $0 \%$ \\
\hline 2 & Donkey & $24.13 \%$ & $23.8 \%$ \\
\hline 3 & Mule & $20 \%$ & $0 \%$ \\
\hline Total & & $23.46 \%$ & $21.73 \%$ \\
\hline
\end{tabular}

It was observed that there was different types of housing system for equines in the study area. The infection was recorded high in those horses which were reared in chhapra $(51.51 \%)$ as compared to open (15.97\%) and paka $(24.39 \%)$. In case of donkeys, the infection rate was recorded as $64 \%, 15.97 \%$ and $25.66 \%$ in chhapra, open and paka housing system, respectively. During the study period, only one mule was infected which was reared in chhapra housing system.

During the study period, it was observed that all horses were reared by individuals and no any horse was found stray. The haemoprotozoan infection in horse was noted as 7.69 in reared type horses. The same situation was also found for mules and out of five only one mule was found infected by haemoprotozoan which was also reared by individuals. In case of donkeys, the infection was high in stray donkey $(100 \%)$ as compared to the reared (23.57\%).

\section{DISCUSSION}

Haemoprotozoan diseases including babesiosis, theileriosis and trypanosomiasis are considered having major effect on health and productive performance of equines (Rajput et al., 2005). Protozoan diseases causes substantial losses throughout the world (Ananda et al., 2009; Kakarsulemankhel, 2011) as these have got a serious economic impact due to obvious reasons of mortality, lowered working efficiency (Uilenberg, 1995), and increased cost on control measures (Makala et al., 2003).

During the present study, overall prevalence of haemoprotozoans in equines at district Larkana was recorded as $23.33 \%$. tehsil/ taluka wise infection of haemoprotozoans was recognized higher (25.33\%) in taluka Bakranias compared to Larkana (24\%), Ratodero (22.66\%) 
and Dokri $(21.33 \%)$. The results of this study are somewhat similar to Samad and Gautam (1984), they reported that different blood protozoans such as Babesia, Theileria and Trypanosoma were found in equines in Bangladesh and Trypanosoma was more prevalent in north western region of the Bangladesh. Difference in the prevalence of trypanosomiasis in equines in the present study and their research may be due to different climatic conditions and availability of vectors in the area. Whereas, Babesia was more prevalent in different areas of Bangladesh and its prevalence was recorded as $14.53 \%$ and $70 \%$ by Samad et al. (1989) and Chowdhury et al. (2006), respectively. During the present study the frequency of theileriosis was more in equines as $70 \%$ of the animals were found infected in the study area, this difference may be attributed to the change in environment and availability of the vectors.

During the present study, the frequency percentage of different haemoprotozoans like Theileria, Babesia and Trypanosoma was recorded as 66.67\%, 33.33\% and $0 \%$, respectively, in equines at district Larkana. The result of present study was partially are in agreement to Mahmoud et al. (1999), they investigated 83 horses and 40 donkeys from four climate zone of Jordan. They reported clinical evidence of trypanosomiasis as $9.6 \%$ in horses and overall prevalence as $33.33 \%$ and $0 \%$ in horses and donkeys, respectively. This difference in result may be due to number of samples examined, climatic condition and management systems.

The prevalence percentage of haemoprotozoan was observed as $7.69 \%$ in horses above 2 year of age group. In case of donkeys, infection rate was $24.70 \%$ and $18.51 \%$ in above 2 years and below 2 years age groups, respectively. Age also influences the occurrence of haemoprotozoan diseases. In the present study, higher susceptibility of adult equines to haemoprotozoan diseases were found consistent with the findings of Ananda et al. (2009) who reported that higher prevalence in equines aged more than 3 years, followed by the lower prevalence in 1-2 years of age. Observations of this study are also in agreement with the findings of Kamani et al. (2010) who observed higher prevalence in adult than young equid. The findings of babesiosis in this investigation were supported by the observation of Urquhart et al. (1996); Annetta et al. (2005), they reported an inverse age resistance of the disease where adult showed more susceptibility than young one.

The housing-wise prevalence of blood protozoans was recorded as $51.51 \%, 15.97 \%$ and $24.39 \%$ in chhapra, open and paka construction (cemented), respectively. The variance in housing-wise infection may be due to the availability of cracks for hiding places to vector in chhapra and open area as compared to paka constructed with cement and bricks.

In case of reared and stray equines the result of blood protozoans in present study were high $(100 \%)$ in stray as compared to reared animals $(22.81 \%)$. This difference in infection rate may be due to management because stray animals have free roaming without any attention and care of any attendant. Whereas reared animals have more attention and care by the owners.

\section{CONCLUSION}

In conclusions, it was observed that all the animals from three species were equally susceptible to the protozoal infection with Theileria being more prevalent in all animals. While, no any case of Trypanosoma was recorded which shows absence of their vector or maybe infection is not endemic to these areas. While, production systems also have significant impact on the prevalence of infection. Overall these data provide a baseline data regarding the prevalence of haemoprotozoan infection in northern Sindh which can further be used for planning control strategies for haemoprotozoans.

\section{AUTHOR'S CONTRIBUTION}

M. A. Kumbhar: Conducted research

M. G. Shah: Co-supervised

J. A. Gadahi: Data analysis and write-up of paper

Z. A. Laghari: Provided technical support

M. Kumbhar: Supported in sample collection

\section{REFERENCES}

Adam, K. M. G., J. Paul and V. Zaman. 1971. Medical and veterinary protozoology. Revised edition Churchill Livingstone, Edinburgh and London.

Ali, S., C. Sugimoto and M. Onuma. 1996. Equine Piroplasmosis. Journal of Equine Science, 7 (4): 67-77.

Ananda, K. J., P. E. D'Souza and G. C. Puttalakshmamma. 2009. Prevalence of Haemoprotozoan diseases in crossbred 
cattle in Banglore north. Veterinary World, 2 (1): 1516.

Chowdhury, S., M. A. Hossain, S. R. Barua and S. Islam. 2006. Occurrence of common blood parasites of cattle in Sirajgong Sadar area of Bangladesh. Bangladesh Journal of Veterinary Medicine, 4 (2):143-145.

Fielding, D. 1991. The number and distribution of equines in the world. In: Proceedings of the Colloquium on Donkeys, Mules and horses in Tropical Agricultural Development, Edinburgh, 3: 62-66.

Friedhoff, K. T., A. M. Tenter and I. Muller. 1990. Haemoparasites of equines: Impact on international trade of Horses. Revue Scientific Technique, 9 (4): 1187-1194.

Goraya, K., Z. lqbal, M. S. Sajid and G. Muhammad. 2013. Frequency distribution of equine diseases in three metropolises of the upper Punjab, Pakistan. International Journal of Agriculture and Biology, 15 (6): 1067-1074.

GoP, 2018. Pakistan Economic Survey 2017-18. Ministry of Finance, Government of Pakistan.(http://www.finance.gov.pk/survey_ 1415.html.)

lqbal, Z., M. S. Sajid, A. Jabbar, Z. A. Rao and M. N. Khan. 2006. Techniques in parasitology. Higher Education Commission, Islamabad-Pakistan, pp. 52-54.

Jabbar, A., T. Abbas, Z. U. Sandhu, H. A. Saddiqi, M. F. Qamar and R. B. Gasser. 2015. Tick-borne diseases of bovines in Pakistan: Major scope for future research and improved control. Parasite and Vectors, 8 (283): 1-13.

Joanne, R., C. Ernest, D. C. Mervin, S. Michael and A. David. 2003. A field evaluation of PCR for routine detection of Babesia equi in Horses, Veterinary Parasitology, 114 (2): 81-87.

Kakarsulemankhel, J. K. 2011. Re-description of existing and description of new record of tick Hyalomma, Euhyalomma, schulzei. From Pakistan. International Journal of Agriculture and Biology, 13 (5): 689-694.

Kamani, J., A. Sannusi, O. K. Eqwu, G. I. Dogo, T. J. Tanko, S. Kemza, A. E. Takarki and D. S. Gbise. 2010. Prevalence and significance of haemoparasitic infections of cattle in North-Central, Nigeria. Veterinary World, 3: 445-448.

Krishnamurthy, C. M., K. J. Ananda and J. Adeppa. 2016. Prevalence of Haemoprotozoan infections in bovines of
Shimoga region of Karnataka state. Journal of Parasitic Diseases, 40 (3): 890-892.

Maharana, B. R., A. K. Teswari, B. C. Saravanan and N. R. Sudhakar. 2016. Important hemoprotozoan diseases of livestock: Challenges in current diagnostics and therapeutics: An update. Veterinary World, 9 (5): 487-495.

Mahmoud, N., A. Shehada, H. Anshassi, G. Mustafa and Z. Amrd.1999. Prevalence of Surraamong camels and horses in Jordan. Veterinary Medicine, 38 (4): 289-293.

Makala, L. H., P. Mangani, K. Fujisaki and H. Nagasawa. 2003. The current status of major tick-borne diseases in Zambia. Veterinary Research, 34 (1): 27-45.

Mattioli, R. C., J. Zinsstag and K. Pfster. 1994. Frequency of Trypanosomiasis and intestinal parasites in draught donkeys in the Gambia in relation to animal husbandry. Tropical Animal Health and Production, 26 (2): 102-108.

Mehlhorn, H. and E. Schein. 1998. Redescription of Babesia equi (Laveran, 1901) as Theileria equi. Parasitology Research, 84 (6): 467-475.

Rajput, Z. I, S. H. Hu, A. G. Arijo, H. Habib and K. Khalid. 2005. Comparative study of Anaplasma parasites in tick carrying buffaloes and cattle. Journal of Zhejiang University-Science, 6 (11): 1057-1062.

Salih, D. A, A. M. El Hussein and L. D. Singla. 2015. Diagnostic approaches for tick borne haemoparasitic diseases in livestock. Journal of Veterinary Medicine and Animal Health, 7 (2): 45-56.

Samad, M. A. and O. P. Goutam. 1984. Prevalence of Theileria annulata infection in cattle of Bangladesh. Indian Veterinary Medicine Journal, 13: 50-51.

Samad, M. A., S. A. Bashar, M. Shahidullah and M. U. Ahmed. 1989. Prevalence of Hemoprotozoan parasites in the cattle of Bangladesh. Indian Journal of Veterinary Medicine, 13 (1): 50-51.

Soulsby, E. J. L. 1982. Helminths, Arthropods and Protozoa of domesticated animals, $7^{\text {th }}$ Edition. The English Linguar Book Society and Bailliere Tindal, London, pp: 765-766.

Uilenberg, G. 1995. International collaborative research: significance of tick-borne Hemoparasitic diseases to world animal health. Veterinary Parasitology, 57 (1-3): 1941.

Urquhart, G. M., J. Armour, J. L. Duncan, A. M. Dunn and F. W. Jennings. 1996. Veterinary 
Parasitology, $2^{\text {nd }}$ Edition. Blackwell Science, UK.

Velusamy, R, N. Rani, G. Ponnudurai, T. J. Harikrishnan, T. Anna, K. Arunachalam, K. Senthilvel and P. Anbarasi. 2014. Influence of season, age and breed on prevalence of haemoprotozoan diseases in cattle of Tamil Nadu, India. Veterinary World, 7 (8): 574578.

(Received: June 02, 2019; Accepted: June 29, 2020) 